\title{
Mundo do trabalho: alguns aspectos vivenciados pelos profissionais recém- formados em enfermagem*
}

\author{
The world of work: some aspects experienced by professional nurses recently graduated \\ El mundo del trabajo: algunos aspectos experimentados por profesionales de enfermería recién \\ graduados
}

\author{
Mariza Maria Serafim Mattosinho', Maria Seloi Coelho ${ }^{2}$, Betina Hörner \\ Schlindwein Meirelles ${ }^{3}$, Sabrina da Silva de Souza ${ }^{4}$, Cleonete Elena Argenta ${ }^{5}$
}

\begin{abstract}
RESUMO
Objetivo: Conhecer algumas vivencias de recém graduados em enfermagem, na transição do mundo acadêmico para o mundo do trabalho. Métodos: Pesquisa exploratória descritiva realizada com amostra de 31 profissionais graduados em cursos de enfermagem no período de 2000 a 2004. Resultados: $\mathrm{Na}$ análise e interpretação dos dados, foram identificados três tipos de vivencias: preconceitos no mundo do trabalho, inserção na equipe de trabalho em saúde e fatores que facilitam a transição para o mundo do trabalho. Conclusão: $O$ início da atividade profissional, para o(a) enfermeiro(a), pode ser marcado por dificuldades, gerando ansiedade. Entretanto, o mundo do trabalho pode ser prazeroso, gratificante e instigante, estimulando o profissional a superar os desafios e os próprios limites decorrentes da formação profissional.
\end{abstract}

Descritores: Trabalho; Educação em Enfermagem; Gestão de pessoas

\begin{abstract}
Objective: To know some experiences, of nurses recently graduated, in the transition from academia to the world of work. Methods: It is a descriptive and exploratory study conducted with a sample of 31 professionals graduated in nursing courses in the period $2000-2004$. Results: The analysis and data interpretation identified three types of experiences (prejudice in the world of work, integration into the health work-team and factors that facilitate the transition to the world of work). Conclusion: The beginning of the professional activity, for nurses, could be marked by difficulties that generate anxiety. Meanwhile, the world of work can be enjoyable, rewarding and challenging, encouraging professionals to overcome challenges and constraints that arise from the profession education.
\end{abstract}

Keywords: Work; Nursing education; Management of people

\section{RESUMEN}

Objetivo: Conocer algunas vivencias de recién graduados en enfermería, en la transición del mundo académico para el mundo del trabajo. Métodos: Investigación exploratoria y descriptiva realizada con una muestra de 31 profesionales graduados en cursos de enfermería en el período de 2000 a 2004. Resultados: El análisis e interpretación de los datos identificó tres tipos de vivencias (prejuicios en el mundo del trabajo, inserción en el equipo de trabajo en salud y factores que facilitan la transición para el mundo del trabajo). Conclusión: El inicio de la actividad profesional, para el enfermero, puede ser marcada por dificultades que generan ansiedad. Entre tanto, el mundo del trabajo puede ser placentero, gratificante e provocativo, estimulando al profesional a superar desafíos y límites, provenientes de la formación profesional. Descriptores: Trabajo; Educación en Enfermería; Gestión de personas

\footnotetext{
* Parte da pesquisa "Transição da Enfermagem Acadêmica para a Enfermagem no Mundo de Trabalho", desenvolvida no Núcleo de Estudos e Assistência em Enfermagem e Saúde às Pessoas com Doenças Crônicas (NUCRON) vinculado ao Curso de Pós-Graduação em Enfermagem da Universidade Federal de Santa Catarina - UFSC Florianópolis (SC), Brasil.

${ }^{1}$ Mestra em Enfermagem. Enfermeira da Secretaria de Estado da Saúde - Departamento de Educação em Serviço - Florianópolis (SC), Brasil.

${ }^{2}$ Doutora em Enfermagem. Enfermeira da Secretaria de Estado da Saúde Florianópolis (SC), Brasil.

${ }^{3}$ Doutora em Enfermagem. Professora do Curso de Graduação e de Pós-Graduação em Enfermagem da Universidade Federal de Santa Catarina - UFSC Florianópolis (SC), Brasil.

${ }^{4}$ Pós-graduanda (Doutorado) pelo Programa de Pós-Graduação em Enfermagem da Universidade Federal de Santa Catarina - FSC Florianópolis (SC), Brasil. Enfermeira da Secretaria Municipal de Saúde de São José e da Emergência do Hospital Universitário - Florianópolis (SC), Brasil.

${ }^{5}$ Enfermeira Especialista da Secretaria de Estado da Saúde - Escola de Saúde Pública - Florianópolis (SC), Brasil.
} 


\section{INTRODUÇÃO}

A passagem da condição de estudante para a de profissional pode provocar estresse em enfermeiros recém-formados. Rápidas mudanças ocorrem ao iniciarem o exercício profissional, pois geralmente se deparam com a incongruência entre o aprendizado ideal adquirido na academia e a realidade encontrada no ambiente de trabalho ${ }^{(1-2)}$.

O conflito entre a academia e o serviço na enfermagem não é novidade, pois nas últimas cinco décadas a literatura tem mostrado reflexões sobre o tema e sugestões e alternativas de solução, muitas delas sem sucesso. Esse problema, no entanto, não ocorre exclusivamente na enfermagem. Há conflito similar no serviço social, na educação e em outras profissões ${ }^{(3)}$.

O conflito na enfermagem foi descrito como uma síndrome denominada choque da realidade ${ }^{(3)}$. Este choque ocorre quando profissionais recém-formados não conseguem integrar o conhecimento obtido na escola com sua prática cotidiana, ou seja, descobrem que a enfermagem aprendida na academia não é a mesma praticada nas instituições de saúde, isto é, não está fundamentada nos mesmos paradigmas. $\mathrm{O}$ modelo de assistência utilizado nas instituições hospitalares é o que mais diverge da orientação teórica da academia ${ }^{(4)}$.

Além disso, as instituições de saúde, geralmente, designam os recém-formados para postos de chefia, com a responsabilidade de liderar o trabalho de técnicos e auxiliares de enfermagem com larga experiência e habilidades técnicas. Diante de tal situação, os recémformados, por não terem ainda desenvolvido tais habilidades, sentem-se inseguros e insuficientemente preparados para enfrentar a realidade ${ }^{(5)}$. Por outro lado, os técnicos e auxiliares de enfermagem sentem-se excluídos do conhecimento acadêmico dos enfermeiros e, desta forma, podem reagir com frustração e hostilidade. No decorrer de nossa experiência profissional, observamos que a maioria dos alunos de enfermagem tem desaprovado a prática como está sendo conduzida nas instituições de saúde e tem criticado a atitude dos profissionais de enfermagem no campo do trabalho. Observamos, também, que esses mesmos alunos, ao serem inseridos no mundo do trabalho, comportavamse do mesmo modo daqueles por eles desaprovados e, por sua vez, passavam a ser criticados pelos estudantes que os sucediam. O descompasso entre o ensino acadêmico e as expectativas no campo de trabalho tem sido denunciado por alunos de enfermagem ${ }^{(6)}$.

Diante dessa situação, percebemos que poucos estudos estão abordando essa temática, surgindo então o questionamento: como acontece a transição dos enfermeiros recém-formados do mundo acadêmico para o campo do trabalho?
Assim, traçamos o seguinte objetivo para este estudo: conhecer algumas vivencias de enfermeiros recém formados na transição do mundo acadêmico para o mundo do trabalho.

\section{MÉTODOS}

Trata-se de uma pesquisa de abordagem qualitativa, exploratória e descritiva. A amostra foi do tipo conveniência, constituída de 31 enfermeiros selecionados a partir dos seguintes critérios de inclusão: formados em cursos de graduação em Enfermagem de Santa Catarina no período de 2000 a 2004, por serem considerados recém-formados e terem experenciado a situação recentemente; atuando em instituições de saúde da Grande Florianópolis (hospitais e centros de saúde); que aceitaram participar do estudo. Esses profissionais foram identificados a partir de uma lista de enfermeiros, fornecida pelas instituições de saúde da Grande Florianópolis. Posteriormente foram contatados por telefone ou pessoalmente e convidados a participar do estudo. Após as explicações sobre o estudo e, previamente às entrevistas, efetuaram a leitura e assinatura do Termo de Consentimento Livre e Esclarecido.

As informações foram obtidas de setembro a dezembro de 2006, através de entrevistas semiestruturadas, com questões abertas e fechadas, gravadas em fita cassete após o consentimento dos entrevistados e, posteriormente, transcritas para análise.

Foi realizada a análise qualitativa, com a exploração do material (codificação das entrevistas) tratamento dos resultados obtidos (criação das categorias e interpretação dos significados). Para a organização dos dados, foi utilizado o software denominado de Atlas Ti (Qualitative Research and Solutions - Non-numeric and Unstructured Data - Index, Searching and Theorizing), que se destina à análise de dados não numéricos e não estruturados, que se possam indexar, buscar e, a partir deles, teorizar. Tal programa é projetado de modo a permitir o armazenamento, a exploração e o desenvolvimento de idéias e/ou teorias sobre os dados. Este programa auxiliou na codificação dos dados permitindo-nos o primeiro nível de análise, que foi estabelecido a partir da leitura exaustiva das entrevistas, nas quais identificamos elementos significativos, que não eram mais os dados brutos, mas códigos, gerando assim, as categorias prévias de análise.

O projeto atendeu à Resolução no ${ }^{\circ}$ 196/96 do Conselho Nacional de Saúde do Ministério da Saúde( ${ }^{(7)}$, sendo aprovado pelo Comitê de Ética em Pesquisa com Seres Humanos da Universidade Federal de Santa Catarina, com o Certificado de Apresentação para a Apreciação Ética $n^{\circ}$. 0161.0.242.000-06. A fim de preservar o anonimato e a confidencialidade, as falas dos participantes foram identificadas no texto com a letra P. 


\section{RESULTADOS}

Os sujeitos identificados pela busca ativa nas instituições de saúde foram graduados, quase todos, em quatro diferentes instituições de Santa Catarina. Somente dois provêm de outros Estados: um formado no Rio Grande do Sul e o outro na Bahia. Constatou-se, também, que mais de $90 \%$ eram do sexo feminino. As atividades profissionais começaram em hospital para 39\%; no Programa de Saúde da Família para 20\%; nas Secretarias de Saúde 19,5\%; em instituições de ensino 15,4\%, nas quais ministram aulas em cursos técnicos de enfermagem ou superior de enfermagem.

O campo de trabalho em saúde é altamente complexo e dinâmico, o que faz com que os profissionais desta área, ao iniciarem suas atividades, vivenciem diferentes aspectos em sua prática cotidiana.

Ao analisar e interpretar os dados da pesquisa, foram constituídas três categorias, assim definidas: preconceitos vivenciados no mundo do trabalho, a inserção na equipe de trabalho em saúde e fatores que facilitam a transição para o mundo do trabalho.

Preconceitos vivenciados no mundo do trabalho

Como recém-formados, os enfermeiros referiram vivenciar situações de preconceito no seu primeiro trabalho. Essa manifestação estava relacionada a outros profissionais da equipe de enfermagem, a médicos e até mesmo aos usuários dos serviços de saúde. Vivenciaram situações de preconceito referente à idade e à inexperiência profissional.

O maior preconceito enfrentado no início das atividades profissionais foi com relação à idade, por serem jovens e inexperientes, fazendo com que outros profissionais tivessem resistência em aceitá-los, não confiando no seu saber e habilidade. Situações estas que deveriam ser conquistadas no quotidiano da atividade profissional.

Tués muito novinha, tu não passas confiança, né. Tu teres que no dia-a-dia lutar e mostrar, não sópara o paciente que está ali precisando de ti, mas para todos da tua equipe que realmente você sabe. (P26).

Esse preconceito foi além da equipe de trabalho, manifestando-se também nas pessoas atendidas pelo profissional, que se mostravam inseguras, não confiando nas orientações recebidas e nos cuidados prestados e, muitas vezes, preferindo confiar em outros membros da equipe de enfermagem por serem mais velhos.

Às vezes, eu sofria preconceito dos pacientes, 'tão novinha'. Às vezes não perguntavam suas dúvidas para mim e sim para os técnicos e auxiliares. (P6)

A gente queria fazer as orientações de saúde, tudo com os pacientes e percebia que eles não respeitavam muito às tuas opiniōes, às tuas orientacões, ser nova, por ter menos idade e menos experiência. Eu acho que no começo sofria mais preconceito. (P7).

Imerso nas relações de trabalho, que se iniciam, o enfermeiro vivencia as relações de poder, de forças, de enfrentamentos ${ }^{(7)}$. A presença de um novo membro vai influenciar nas relações existentes na equipe, podendo ser percebida, algumas vezes, como ameaça, resultando em sentimentos de rejeição. A rejeição sentida pelos participantes do estudo dificultou a transição para o mundo profissional. O sentimento de insegurança, a necessidade de aprender, de ser apoiado, aceito e respeitado pela equipe foram fatores muito presentes na adaptação dos profissionais ao primeiro emprego.

\section{Inserção na equipe de trabalho em saúde}

Ser aceito e acolhido pela equipe de trabalho é um passo importante para o bom funcionamento do serviço, bem como para a satisfação profissional. A transição da academia para o campo de trabalho pode gerar momentos de insegurança pessoal no enfrentamento do "desconhecido" e na necessidade de familiarização com a nova aceitação. Agora, graduados em enfermagem, o sentimento de responsabilidade aumenta, não há mais a presença de um professor para orientar e responsabilizarse pelas atividades, é o momento de enfrentar a situação.

Foi bem difícil, porque para tu conseguires te integrar à equipe é complicado, porque não sabes o que os outros estão pensando. Como estudante é uma coisa, mas, depois, trabalbando, a responsabilidade é pior, não foi tão simples assim. (P1)

A inserção na equipe é marcada pela busca da integração, do fazer parte e ser visto como um ser, também fundamental do corpo de enfermagem. Entre os participantes da pesquisa, observou-se que a inserção, no que se refere à recepção e acolhimento, foi considerada como positiva pela maioria.

O acolhimento foi bom assim, porparte lá do Centro de Saúde, o pessoal me recepcionou muito bem. (P9).

Sempre fui muito abraçada pelos colegas em todos os locais de trabalho, eu nunca me senti rejeitada. (P11).

A integração na equipe é facilitada quando as pessoas gostam do que fazem e estão abertas para trabalhar em equipe, sempre compartilhando as informações, e desenvolvendo as atividades em parceria. Os funcionários que já trabalham no local surgem como pessoas que ajudam a conhecer as normas e rotinas da instituição e contribuem no treinamento inicial. Às vezes, a sensação é comparada à da adoção:

Quem me acolheu foi a equipe, quem me treinou foi a equipe de enfermagem. Na verdade eles me adotaram. (P6). 
Os conhecimentos que surgiam da prática profissional foram referidos como uma experiência que não se aprende na faculdade. Essa vivência é rica de situações cotidianas, marcadas por dificuldades, facilidades e pelos respectivos enfrentamentos. Nesses momentos de construção da vida profissional, a figura do técnico ou do auxiliar de enfermagem aparece como facilitador do aprendizado, abrindo as portas para o enfrentamento do desconhecido.

Muita coisa eu aprendi com os técnicos de enfermagem, coisas que na faculdade não se ensinam. Atividades do dia-a-dia. (P10)

Os enfermeiros que já exerciam atividades em outra categoria profissional apontam para duas situações: a de não aceitação e a de aceitação por parte da equipe. A não aceitação é marcada por sentimentos de desprazer com a ascensão profissional do colega, percebida como uma espera para "puxar o tapete". Os sentimentos negativos acabam, muitas vezes, prejudicando a integração da equipe e comprometendo o desempenho de suas atividades. Já a aceitação é referida como apoio, fato que ajuda a superar as dificuldades. Um gesto, como parabenizar o colega e o acolher em sua nova função profissional, pode ser visto como uma atitude que fortalece os vínculos e os enfrentamentos necessários da nova profissão.

\section{Fatores que facilitam a transição para o mundo do trabalho}

Os entrevistados também referiram algumas situações que facilitaram o enfrentamento ao chegarem à prática, como profissionais. Essas facilidades decorriam principalmente do bom embasamento teórico recebido no curso de graduação. Fazem referência à importância do conhecimento científico aprendido na academia para a segurança de todos os profissionais, principalmente para os recém-formados, ao se depararem com as situações práticas. Referem-se, também, à contribuição da formação de um perfil crítico no estudante, tornando-o um formador de opiniões.

A facilidade é que a teoria dada na universidade foi muito boa. Acho que fui formado e estou bem tranqüilo nisso e que sou formador de opinião, que tive esse aprendizado e isso que acho que é a diferença. (P 8)

É bom que dá pra relacionar a teoria, aquilo que a gente aprendeu na faculdade, com a prática. Sempre dá pra relacionar e tratar o paciente da melhor forma. (P7)

A universidade contribuin com a teoria, tive bastante teoria e pouca prática. Aliei a minha teoria para exercer a minha prática. Acho que foi isso que me ajudon a ultrapassar as dificuldades. (P5)

Outra facilidade encontrada diz respeito ao serviço de saúde, ora pela própria instituição, ora pelos profissionais que ali se encontravam. As contribuições das instituições eram referentes à liberação e facilitação para participação em atividades de aprendizado profissional, bem como à criação de um ambiente com liberdade para o profissional atuar.

[...] os cursos de capacitação oportunizaram a liberdade de trabalhar no PSF (Programa de Saúde da Família). Foi uma experiência bem positiva, senti facilidade, liberdade de atuar. Quando se tem liberdade fica tudo mais fácil. (P2).

A equipe de trabalho aparece como apoio nas questões práticas do relacionamento com as pessoas atendidas.

A equipe com a qual eu trabalhava me ajudou, eles me deram bastante apoio no trato com o paciente. Acho que foi isso que facilitou. $E$ a questão da teoria a gente tem bastante. (P5)

Aparece como facilitador, também, o fato de o primeiro emprego ocorrer na instituição na qual o enfermeiro já teve uma experiência, seja como aluno ou como estagiário, pois já conhece as técnicas, rotinas e os profissionais que lá atuam, reduzindo o estresse do novo emprego, o medo do desconhecido, a insegurança, facilitando a inserção profissional.

[...] a facilidade que tive é que o meu primeiro emprego foi no campo de estágio. Então, pra mim foi ótimo, fiz dois anos de estágio lá e logo em seguida já fui enfermeira! Ai, indo pro hospital foi mais tranqüilo ainda, porque já sabia algumas técnicas. Então, o pessoal lá foi bem receptivo, assim, quanto a isso não teve problema. Mas, acredito que esse não-problema foi por causa desse estágio de dois anos que fiz nessa clínica, em que eu treinava muito, tanto em Centro Cirúrgico quanto em um estágio anterior a esse. Fiz estágio em CC também. (P12)

A realização de estágios extracurriculares em instituições diferentes auxilia na formação técnica e faz o aluno vivenciar realidades profissionais, muitas vezes diferentes, dando-lhe a oportunidade de visualizar as particularidades de cada instituição, bem como as de cada área de atendimento de enfermagem, deixando-o mais preparado para o exercício da profissão.

Acho que facilitou ter feito estágio em várias instituições diferentes, porque consegues conhecer a realidade de cada um é quando tu vens mais preparada. (P31)

Outro ponto levantado foi sobre o cuidado de enfermagem. Embora não tivessem ainda habilidade para realizarem alguns procedimentos técnicos, os enfermeiros entendiam que a academia estimulou e proporcionou o contato com as pessoas que cuidavam, o que deu segurança nas abordagens, quando iam realizar qualquer procedimento. 
A facilidade é que, como durante a faculdade já tive mais contato com o paciente, com o mundo do hospital que sempre amei de paixão. Então, pra mim, isso tudo é muito fácil assim. (P24)

Acho que a academia me proporcionou bastante contato com o cuidado com os pacientes. Embora, às vezes, não tenhamos realizado o procedimento, mas o fato de estar com o paciente, conversando, interagindo, isso eles me proporcionaram, o que facilitou bastante o contato com o paciente como profissional. (P21)

As falas dos participantes deste estudo evidenciaram que o conhecimento teórico, o perfil crítico, mesmo diante das deficiências no conhecimento prático, propiciados na formação acadêmica, associados às possibilidades de educação continuada oferecidas pelas instituições em que se inserem, propicia a transição e o desenvolvimento profissional. Não são relegados os conhecimentos anteriores sobre o tipo de serviço e as características das instituições, que propiciam que as relações interpessoais se estabeleçam com mais facilidade e sirvam de sustentação nas ações e inserção no trabalho.

\section{DISCUSSÃO}

A inexperiência profissional e a deficiente habilidade instrumental, associadas ao fato de ser jovem, trazem para o enfermeiro um desafio maior; o de lidar com os recursos humanos da instituição, principalmente porque ele ocupa um espaço de liderança dentro da equipe de enfermagem, ocasionando um descontentamento aos profissionais mais antigos e experientes, que, muitas vezes, mostram-se resistentes à idéia de ter como líder uma pessoa mais jovem e sem experiência prática.

As situações de preconceito vivenciadas pelos enfermeiros são causadoras de dificuldades para a inserção no mundo do trabalho. Ao mesmo tempo em que criam obstáculos, estimulam a superação, servindo como fatores motivacionais para a busca da afirmação profissional. Essas situações são superadas com a demonstração de competência e saber associados ao desenvolvimento da experiência prática. Assim, cada profissional vai construindo uma história, criando uma imagem, buscando o seu espaço e respeito.

Os sentimentos podem nos levar a comportamentos que geram harmonia ou desarmonia do ambiente ${ }^{(8)}$. O sentimento de rejeição pode levar a dificuldades no relacionamento e ao desenvolvimento de um ambiente hostil, de insatisfação. A enfermagem, por ser uma profissão que trabalha em equipe, necessita de um ambiente de harmonia, de respeito e de integração nas relações de trabalho e nas atividades a serem desenvolvidas. O grau de prazer e satisfação com as atividades que exercemos vai nos impulsionar para o aperfeiçoamento profissional. Os sentimentos de aceitação ou rejeição podem ser marcos para desencadear uma série de situações que determinam a prática profissional.

A aceitação, às vezes, é marcada pela demonstração do conhecimento, da segurança e principalmente da competência profissional. Aos poucos, a inserção vai ocorrendo com simpatia e companheirismo.

O ser humano tem necessidade de fazer parte de um meio, de ser aceito e de inserir-se no contexto. A felicidade pessoal e profissional depende desta aceitação. O prazer e o amor por uma atividade de trabalho estão relacionados com o ambiente de realização desta. Portanto, a inserção como uma necessidade de acolhimento e aceitação do novo membro da equipe é essencial, não somente para o bom desenvolvimento profissional, mas também para uma construção do significado do trabalho.

A valorização do processo criativo, promovendo uma formação crítica, sensível, comprometida com a população, são fatores indispensáveis para a educação em enfermagem voltada para atender às exigências colocadas pelo contexto de contínuas mudanças sociais ${ }^{(9)}$.

As contribuições acadêmicas trazem consigo uma sensação de conforto para o profissional, dando-lhe subsídios para superar as situações novas. Com a integração teoria-prática, os enfermeiros buscavam dar o seu melhor no atendimento de enfermagem.

As facilidades de inserção no ambiente profissional proporcionadas pela vivência na academia, pela instituição de trabalho ou pelas pessoas que compõem a equipe de enfermagem, são fatores que repercutem na formação do enfermeiro, dando-lhe mais segurança e firmeza para trilhar seu caminho na área de atuação. A construção do saber em enfermagem ocorre no cotidiano profissional, nas relações estabelecidas entre as pessoas da equipe, com as pessoas que cuidam, com outros profissionais e, de forma sistemática, nas escolas de formação ${ }^{(10)}$.

\section{CONSIDERAÇÕES FINAIS}

A realidade do mundo do trabalho é diferente da academia. As condições político-burocráticas e econômicas das instituições, geralmente não permitem que os recém-graduados sejam acompanhados por um profissional veterano. Além disso, as instituições de saúde não dispõem de um programa sistemático de treinamento para profissionais ingressantes. Desta forma, a teoria concebida na academia fica falando para si mesma e a prática, muitas vezes, é desenvolvida com base no "acerto e erro", o que gera, para os enfermeiros recém formados, situações de estresse.

O início da atividade profissional pode ser marcado por dificuldades, como os preconceitos relacionados à falta de experiência e a pouca idade, geradores de ansiedade nos enfermeiros, que buscam sua afirmação e o respeito como profissionais. Ao mesmo tempo, essa situação estimula-os a fortalecerem seus conhecimentos 
técnico-científicos e a desenvolverem o manejo com pessoas, para conquistarem um espaço. A inserção e a aceitação na equipe, como profissional, é uma meta do novo enfermeiro, a ser conquistada com a demonstração de competência, saber, humildade e companheirismo, fatores essenciais para um bom profissional.

O mundo do trabalho, para os enfermeiros recémformados, pode representar uma situação de estresse. Ao mesmo tempo em que estes ficam ansiosos para iniciar as atividades profissionais, sentem medo do desconhecido. Alguns fatores podem atuar como facilitadores na transição da academia para a vida profissional, como a formação acadêmica voltada para a realidade prática, a realização de estágios extracurriculares, a postura institucional de estímulo ao desenvolvimento educativo e o apoio dos demais membros da equipe de enfermagem.

A formação técnico-científica tem sua importância, mas a aproximação com as situações de vida e saúde das pessoas, as formas de significar saúde e doença nos diferentes grupos sociais são algumas particularidades que contribuem para um olhar profissional mais amplo. Os diferentes olhares sobre a complexidade que envolve a formação incluem a aproximação da teoria com a prática, favorecida pela experiência durante estágios

\section{REFERÊNCIAS}

1. Riddell D, Hubalik K. Bridging the gap: responsibility of education or service? In: McCloskey JC, Grace HK. Current issues in nursing. London: Blackwell Scientific Publication; 1983.

2. Gabrielli JMW. Formação do enfermeiro: buracos negros e pontos de luz [tese]. Ribeirão Preto: Escola de Enfermagem de Ribeirão Preto da Universidade de São Paulo; 2004.

3. Kremer M. Why does reality shock continue? In: McCloskey JC, Grace HK. Current issues in nursing. London: Blackwell Scientific Publication; 1983.

4. Ojeda BS, Santos BRL, Eidt OR. A integração ensino e assistência na enfermagem: delineando possibilidades para uma prática contextualizada. Acta Paul Enferm. 2004;17(4):432-8.

5. Erzinger AR. A formação universitária para uma prática social transformadora do profissional de enfermagem na visão de enfermeiras e enfermeiros [dissertação]. Curitiba: Pontifícia extracurriculares.

Percebemos que, mesmo deparando-se com situações que não foram aprendidas na academia, os enfermeiros encontram uma maneira de enfrentá-las, realizando as atividades da melhor forma possível, com bom senso, generosidade, sabendo ouvir e tentando conhecer um pouco do que o outro pensa. Acreditamos que a formação de profissionais competentes necessita estar alicerçada em abordagens que valorizem, não só a racionalidade, mas principalmente a subjetividade, porque é com ela que a enfermagem está diariamente envolvida ao trabalhar com seres humanos, que são imprevisíveis por natureza.

Situações difíceis sempre vão surgir no desenvolvimento profissional, momentos nos quais serão necessários posicionamentos e tomadas de decisões que podem ser muito importantes para a vida de outras pessoas. O preparo da academia é o início, pois o profissional deve estar em constante aprendizado, buscando o desenvolvimento da habilidade, dos conhecimentos, das atitudes e da experiência necessária na qualificação do enfermeiro. Assim, a transição para mundo do trabalho pode ser prazerosa, gratificante e instigante, estimulando o profissional a superar os desafios e os limites de sua formação profissional.

Universidade Católica do Paraná; 2002.

6. Bebrens MA. Formação continuada dos professores e a prática pedagógica. Curitiba: Champagnat; 1996.

7. Lunardi Filho WD, Lunardi VL, Spricigo J. O trabalho da enfermagem e a produção da subjetividade de seus trabalhadores. Rev Latinoam Enferm. 2001;9(2):91-6.

8. Stork RY. Fundamentos de antropologia: un ideal de la excelencia humana. 2a ed. Navarra: Eunsa; 1996.

9. Souza FGM, Terra MG, Reibnitz KS, Backes VMS. Educação em saúde, enfermeiros e criatividade: a interconexão necessária para o processo educativo. Online Braz J Nurs (Online). [ Internet]. 2007 [citado 2007 Set 18]; 6(2): [cerca de 10 p.]. Disponível em: http:/ / www.uff.br/objnursing/viewarticle.php?id $=546 \&$ layout $=\mathrm{html}$

10. Rosa IM, Cestari ME. A relação com o aprender de enfermeiras e estudantes de enfermagem. Online Braz J Nurs [Internet]. 2007 [citado 2007 Set 18]; 6(2): [cerca de 10 p.]. Disponível em: http:// www.uff.br/objnursing $/$ viewarticle.php?id $=546 \&$ layout $=\mathrm{html}$ 